\title{
Systemic and cardiac susceptibility of immune compromised mice to doxorubicin
}

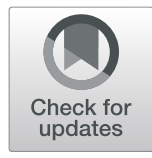

Amanda J. Favreau-Lessard', Hagen Blaszyk², Michael A. Jones², Douglas B. Sawyer ${ }^{1,3}$ and IIka M. Pinz ${ }^{1 *}$

\begin{abstract}
Background: Anthracycline chemotherapy is an effective and widely used treatment for solid tumors and hematological malignancies regardless of its known cardiotoxicity. The mechanisms of the cardiotoxicity are not fully understood and methods to protect the heart during or following anthracycline chemotherapy are currently unclear. In order to examine the efficacy of human cell based therapy in anthracycline-induced injury, we characterized a mouse model using an immune compromised strain of mice capable of accepting human cells.

Methods: Immune compromised mice (NOD.Cg-Prkdc ${ }^{\text {scid }} \| 2 \mathrm{rg}^{\mathrm{tm} 1 \mathrm{Wjl} / \mathrm{Sz} J)}$ were repeatedly exposed to pharmaceutical grade doxorubicin $(0.5 \mathrm{mg} / \mathrm{kg}-4 \mathrm{mg} / \mathrm{kg})$. Cardiotoxicity was assessed by echocardiography and $\mu \mathrm{CT}$ imaging of the coronary vascular bed as well as by flow cytometry and by histological assessments of anthracycline-induced cardiac tissue damage.

Results: The immune compromised mice were highly susceptible to doxorubicin treatment. Doxorubicin induced both systemic and cardiac toxicities. Gastrointestinal and hepatic injury occurred at $4 \mathrm{mg} / \mathrm{kg}$ and $1.5 \mathrm{mg} / \mathrm{kg}$ dosing while mice receiving $0.5 \mathrm{mg} / \mathrm{kg}$ weekly only displayed hepatic damage. Repeated exposure to $0.5 \mathrm{mg} / \mathrm{kg}$ anthracyclines resulted in cardiac toxicity. Flow cytometric analysis of hearts indicated a loss in endothelial and cardiac progenitor cells after doxorubicin treatment. This endothelial loss is corroborated by the lack of small vessels detected by $\mu \mathrm{CT}$ in the hearts of mice exposed to doxorubicin. Histological assessment shows no overt cardiomyocyte injury but livers from mice treated with doxorubicin show marked hepatic plate atrophy with intracytoplasmic and canalicular cholestasis, rare pericentral hepatocellular necrosis and significant zone 3 iron accumulation, likely an indication of metabolic injury due to doxorubicin toxicity.
\end{abstract}

Conclusions: Immune compromised mice are sensitive to doxorubicin therapy resulting in systemic complications in addition to cardiovascular toxicity. Anthracycline-induced cardiotoxicity is observed at very low doses in NOD.CgPrkdc ${ }^{\text {scid }} \| 2 \mathrm{rg}^{\mathrm{tm} 1 \mathrm{Wjl}} / \mathrm{Sz} \mathrm{J}$ mice.

Keywords: Anthracycline cardiotoxicity, Doxorubicin, Immune compromised mice

\section{Background}

Currently, there are over 15 million cancer survivors in the United States, which amounts to almost $5 \%$ of the country's population [1]. This number is projected to double by 2040 [1]. Long-term survivors of cancer are faced with new challenges caused by cytotoxic cancer therapies. In particular, heart disease risk is increased in long-term cancer survivors treated with anthracyclines

\footnotetext{
*Correspondence: pinzi@mmc.org

${ }^{1}$ Maine Medical Center Research Institute, Center for Molecular Medicine, 81

Research Drive, Scarborough, ME 04074, USA

Full list of author information is available at the end of the article
}

(i.e. Adriamycin also known as doxorubicin, Idarubicin, or Daunorubicin), a class of anti-tumor antibiotics that intercalate into DNA to inhibit synthesis thus inducing DNA damage and halting cell proliferation [2]. Anthracyclines are commonly administered as a therapeutic in adult and pediatric oncology due to its efficacy in treating a variety of solid and liquid based cancers such as leukemia, lymphoma, breast cancer, and lung cancer [3] regardless of the known side effects on the heart $[4,5]$.

In order to determine protective interventions for the heart due to anthracycline-induced cardiotoxicity (ACT), animal models of ACT have been developed that mirror the human disease. Many studies have investigated

(c) The Author(s). 2019 Open Access This article is distributed under the terms of the Creative Commons Attribution 4.0 International License (http://creativecommons.org/licenses/by/4.0/), which permits unrestricted use, distribution, and 
potential mechanisms of anthracycline-induced cardiac injury, to include myocyte death, increases in reactive oxygen species, and vascular damage [2]. Transgenic mouse models of ACT have been developed in a variety of mouse strains to investigate the role of a specific gene of interest [6-9]. It is difficult to identify a common mechanism of injury with the current published studies because the study design, dosing, length of treatment, severity of injury, and endpoints vary and therefore make comparisons between studies difficult.

More recently, cell therapies have been proposed to rescue the heart of individuals with anthracycline-induced cardiomyopathy. The lack of preclinical animal models examining these strategies may limit the success of clinical trials. The goal of our study was to develop a mouse model of ACT that mimics the human treatment regimen with repeated weekly anthracycline exposure, because the repeated stress and insult patients undergo may be a contributing factor for developing heart failure. In addition, we used an immune compromised mouse strain (NOD.Cg-Prkdc ${ }^{\text {scid }}$ Il $2 \mathrm{rg}^{\mathrm{tm} 1 \mathrm{~W} / \mathrm{l}} / \mathrm{SzJ}$ ) to enable future cell-based therapeutic approaches using primary human derived cells in the setting of ACT.

\section{Methods}

\section{Animals}

Male and female NOD.Cg-Prkdc $c^{\text {scid }} \mathrm{Il}_{2 \mathrm{rg}^{\mathrm{tm} 1 \mathrm{~W}_{\mathrm{jl}}} / \mathrm{SzJ}}$ (NOD/Scid) mice were purchased from The Jackson Laboratory and housed in an AAALAC-accredited Clean Barrier Animal Facility. All animals and protocols were approved by Maine Medical Center Research Institute's IACUC review committee. Pharmaceutical grade doxorubicin hydrochloride (2 $\mathrm{mg} / \mathrm{mL}$ ) was purchased in solution from Patterson Veterinary (Devens, MA). On the day of treatment, doxorubicin was diluted in $0.9 \%$ pharmaceutical grade saline for intraperitoneal injection. Mice were weighed and the doxorubicin dose was calculated based on body weight, thus injection volumes varied from 50 to $150 \mu \mathrm{L}$. Control mice received saline injections with volumes equivalent to the doxorubicin volume per body weight. The method of administration via intraperitoneal injection was selected after consulting with the Maine Medical Center Research Institute's Animal Care and Use Committee as the safest and most consistent method of repeated injections of doxorubicin.

\section{Study design}

A total of three studies were performed with different weekly doses (Table 1). Study I tested weekly injections of $4 \mathrm{mg} / \mathrm{kg}$ up to a cumulative dose of $8 \mathrm{mg} / \mathrm{kg}$. Study II was designed as a dose escalation study to find the best tolerated dose. Study 3 then tested the best tolerated dose with repeated weekly injections to determine the timeframe for heart failure to be detected.

\section{Flow cytometry}

Hearts from mice were perfused with PBS containing heparin. Ventricular tissue was minced and incubated in a solution of Dispase II/Collagenase II/DNase $\mathrm{I} / \mathrm{CaCl}_{2}$ at $37^{\circ} \mathrm{C}$ for $20 \mathrm{~min}$ to collect a single cell suspension of non-myocyte cells from heart ventricles. To analyze differences in endothelial and progenitor cell populations, cell surface antibodies from BioLegend for $\mathrm{CD} 45^{\mathrm{APC} / \mathrm{Cy} 7}$, $\mathrm{Sca} 1^{\mathrm{PE} / \mathrm{Cy} 7}, \mathrm{CD} 31^{\mathrm{APC}}$ and $\mathrm{CD} 105^{\mathrm{PE}}$ were used. VioDye was utilized to stain for Live/Dead cells. All samples were run on the Miltenyi Biotec MACSQuant Cytometer. Analysis was performed using FlowJo V.10.0.8 software.

\section{Cardiac ultrasound}

Echocardiography was performed with a Vevo2100 (VisualSonics), $40 \mathrm{MHz}$ solid-state transducer, and the papillary muscle was used as orientation for the acquisition of short-axis M-mode images. Data were analyzed by the heart function package provided by VisualSonics Systems [10]. Diastolic and systolic LV internal dimensions were measured to evaluate LV structural changes. Fractional shortening and ejection fraction were calculated to determine changes in cardiac function [11].

\section{$\mu \mathrm{CT}$ imaging}

Hearts were perfused with 25\% Microfil (Flow Tech, Inc.) in the Langendorff mode. We used a low flow perfusion (500 $\mu \mathrm{l} / \mathrm{min}$ ) using a syringe pump (Harvard Apparatus) to prevent Microfil from entering the ventricular chambers. Hearts were suspended in PBS until the Microfil hardened. $\mu \mathrm{CT}$ imaging (Scanco VivaCT-40, Scanco Medical, Basserdorf, Switzerland) was performed at $10.5 \mu \mathrm{m}$ resolution, with a voltage of $55 \mathrm{kVp}$ and a current of $145 \mu \mathrm{A}$, which created a $2048 \times 2048$ pixel image matrix. The tomograms were globally thresholded based on X-ray attenuation and used to render binarized 3-D images of the heart. The segmented image was analyzed with the standard Scanco morphology script to measure coronary

Table 1 Design of all three studies

\begin{tabular}{lllll}
\hline Study & Weekly Doxorubicin Dose & Cumulative Doxorubicin Dose & \# Saline Mice & \# Doxorubicin Mice \\
\hline I & $4 \mathrm{mg} / \mathrm{kg}$ & $8 \mathrm{mg} / \mathrm{kg}$ & $14(7 q, 7 \hat{)})$ & $14(7 q, 7 \hat{)})$ \\
II & Dose escalation: $0.5 \mathrm{mg} / \mathrm{kg}$ with weekly increases by $0.5 \mathrm{mg} / \mathrm{kg}$ & $5 \mathrm{mg} / \mathrm{kg}$ & $\mathrm{N} / \mathrm{A}$ & $5(3 \hat{0}, 2+)$ \\
III & $0.5 \mathrm{mg} / \mathrm{kg}$ & $3 \mathrm{mg} / \mathrm{kg}$ & $4(2 q, 2 \hat{)})$ & $4(2 q, 2 \hat{)}$ \\
\hline
\end{tabular}


diameter and volume. These data were presented as histograms.

\section{Histology}

Heart and liver tissue were isolated from Study III animals and fixed in $10 \%$ formalin prior to histological processing (Maine Medical Center Research Institute Histology Core Facility). Tissues were embedded in paraffin and sectioned for immunohistological staining. Liver tissue was stained for Hematoxylin \& Eosin (H\&E), Masson trichrome, Reticulin, Iron, PAS and PAS-D. Cardiac tissue was stained for $\mathrm{H} \& \mathrm{E}$ and Masson trichrome. Routine histological methods were used. Images were acquired using a Zeiss Axioskop 40 microscope with a Canon EOS 60D camera at 4-, 10-, and 40-fold magnification.

\section{Statistics}

All statistical analyses were performed using Prism (Version 7.03, GraphPad Software Inc). Specific analyses are listed in figure legends.

\section{Results}

\section{Doxorubicin chemotherapy - systemic effects}

To characterize anthracycline-induced cardiotoxicity in this specific mouse strain, we completed three separate studies with varying anthracycline dosages. Study I was designed with a dose of $4 \mathrm{mg} / \mathrm{kg} /$ week with a cumulative dose of not more than $24 \mathrm{mg} / \mathrm{kg}$. This was based on literature findings, mostly from tumor studies, because cardiotoxicity studies are not routinely performed in this immune compromised strain. In the days following the first round of chemotherapy, all doxorubicin mice began exhibiting signs of distress and rapid weight loss (Fig. 1a). After the second round of chemotherapy all doxorubicin mice showed worsening signs of illness including rapid decline in body weight, diarrhea, ruffled fur, and hunching. The study was terminated early. Upon euthanizing mice, we observed severe gastrointestinal inflammation with pockets of air visible within the intestines, and some mice had areas of necrosis in their intestines, consistent with severe intestinal mucositis (Fig. 1d). In addition to the intestinal distress, we observed ascites and severe hepatotoxicity. These unanticipated effects appeared to account for the rapid decline in health, and not cardiac toxicity (Table 2).

Based upon these findings, Study II was conducted to better characterize the dose tolerance and the maximum cumulative dose for this strain of mice. Mice received $0.5 \mathrm{mg} / \mathrm{kg}$ as a first dose and every week the dose increased by $0.5 \mathrm{mg} / \mathrm{kg}$ until the mice showed early signs of distress, such as modest loss of body weight (Fig. 1b). Doses of $0.5 \mathrm{mg} / \mathrm{kg}$ and $1.0 \mathrm{mg} / \mathrm{kg}$ were tolerated well. However, at the dose of $1.5 \mathrm{mg} / \mathrm{kg}$ (cumulative dose of 3 $\mathrm{mg} / \mathrm{kg}$ ) mice started to show a hunched posture. To reach our goal of repeated exposure to anthracyclines, we reduced the dose to $1 \mathrm{mg} / \mathrm{kg}$ for the final two rounds of chemotherapy. After reaching a cumulative dose 5 $\mathrm{mg} / \mathrm{kg}$, mice had lost $16.34 \pm 9.634 \%$ of body weight, had ruffled fur and diarrhea. We determined this as the maximum cumulative dose this strain of mice can tolerate. This cumulative dose was also sufficient to induce cardiotoxicity (Table 3).

We conducted Study III using a very low dose of 0.5 $\mathrm{mg} / \mathrm{kg}$ repeated weekly injections. This low dose is roughly $1 / 20$ the dose given to patients based off the Adriamycin product information [3] and 1/8 the dose used in many mouse studies [12]. Considering the results of Study II, we chose $3 \mathrm{mg} / \mathrm{kg}$ as the maximum cumulative dose. This regimen was tolerated well with male mice starting to slowly lose body weight after 4 weeks. This was in contrast to female mice, which were able to maintain their body weight until the end of the study after six injections (Fig. 1c). Both genders of mice were able to maintain their body weight after doxorubicin treatment stopped at 6 weeks and there was no apparent distress observed in any of the mice. Echocardiography was performed at the five-week time point and confirmed cardiotoxicity (Table 4). Two days prior to the endpoint at 8 weeks, all doxorubicin mice declined rapidly within $24 \mathrm{~h}$ of one another and either died or had to be euthanized due to severe distress.

\section{Cardiac ultrasound}

Cardiac morphology and function were assessed in all three studies (Tables 2-4). In study I, mice showed changes in ventricular morphology that are consistent with cardiac edema. Wall thickness increased in anterior and posterior walls of the left ventricle, causing diastolic and systolic left ventricular volumes to decrease.

In study II, we observed changes in cardiac function and morphology that are consistent with heart injury induced by ACT (Table 3). After 5 weeks of treatment at $3 \mathrm{mg} / \mathrm{kg}$ cumulative dose (echocardiography was performed prior to the 5th injection) all doxorubicin treated mice show thinning of left ventricular walls, lower ejection fraction as well as decreased cardiac output. These data suggest that for this strain of $\mathrm{NOD} / \mathrm{Scid}$ mice, a cumulative dose of $3 \mathrm{mg} / \mathrm{kg}$ is sufficient to induce ACT.

In study III, this treatment regimen increased systolic volumes in the heart in NOD/Scid mice already after 5 weeks and a cumulative dose of $2 \mathrm{mg} / \mathrm{kg}$ (the week 5 echocardiography was performed prior to the 5th injection) as well as a decrease in fractional shortening compared to the control mice (Table 4). Figure 2 compares representative M-mode images from baseline vs. 


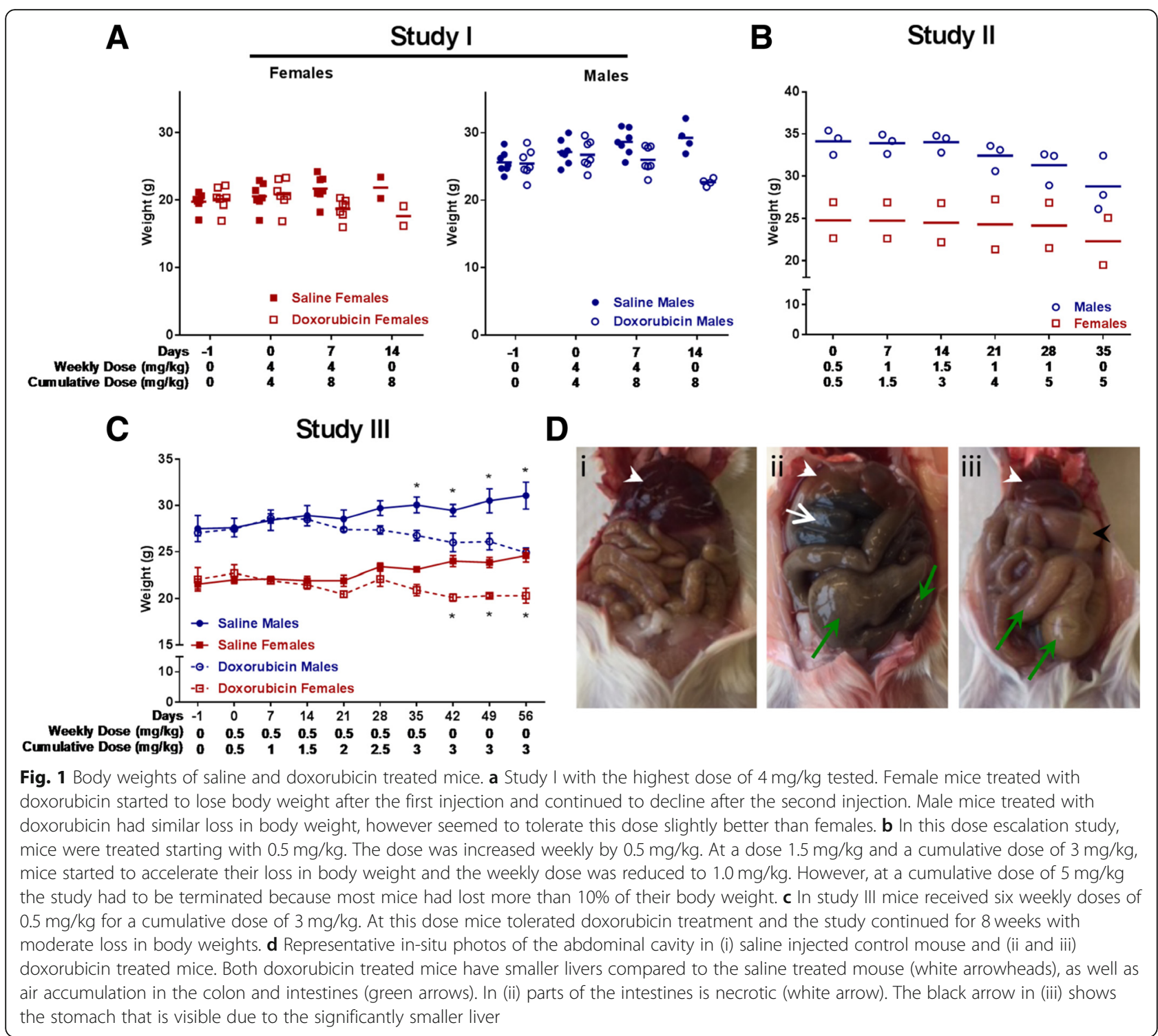

doxorubicin treated hearts showing the increased systolic volume.

\section{Non-myocyte flow cytometry analysis of hearts}

Flow cytometric analysis of non-myocyte cell populations in ventricular tissue was performed of hearts from mice in Study I ( $n=4 /$ treatment). Non-myocyte cells were stained with a mixture of antibodies to identify immune cells and markers of endothelial and cardiac progenitor cells. Dead cells were excluded and live cells were analyzed for the presence of the pan-immune marker, CD45. We observed no significant difference in CD45 expression between saline and doxorubicin treated mice (Fig. 3a). Within the CD45 negative non-immune cell population, cells were analyzed for Sca1 expression, a cell surface marker on both cardiac progenitor and endothelial cells. Doxorubicin treated mice had a significant decrease in $\mathrm{CD} 45^{\text {neg }} \mathrm{Sca}{ }^{\text {pos }}$ cells compared to the saline treated mice (Fig. 3b). Further analysis of the

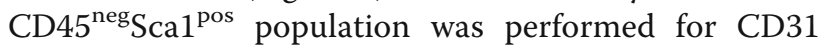
and CD105 expression to distinguish the endothelial and cardiac progenitor populations. Doxorubicin significantly decreased both endothelial $\left(\mathrm{CD} 45^{\text {neg }} \mathrm{Sca} 1^{\text {pos }} \mathrm{CD} 105^{\mathrm{pos}} \mathrm{CD} 31^{\text {pos }}\right)$ and cardiac progenitor $\left(\mathrm{CD} 45^{\text {neg }} \mathrm{Sca} 1^{\text {pos }} \mathrm{CD} 105^{\text {pos }} \mathrm{CD} 31^{\text {neg }}\right)$ populations compared to the saline treated mice (Fig. 3c-d). The loss of endothelial cells suggests damage to the vasculature of the heart. Furthermore, the loss of resident cardiac progenitor cells may suggest that these mice do not have the local progenitor cell pool to repair anthracycline-induced damage in the heart following completion of the chemotherapy regimen. 
Table 2 Study I echocardiography

\begin{tabular}{|c|c|c|c|c|c|c|c|}
\hline \multirow[b]{3}{*}{ Parameter } & \multirow[b]{3}{*}{ Unit } & \multirow{2}{*}{\multicolumn{2}{|c|}{ BASELINE }} & \multicolumn{4}{|c|}{2 weeks } \\
\hline & & & & \multicolumn{2}{|c|}{ CONTROL } & \multicolumn{2}{|c|}{ DOXORUBICIN } \\
\hline & & MEAN & SE & MEAN & SE & MEAN & SE \\
\hline LVAW;d & $\mathrm{mm}$ & 0.83 & 0.04 & 0.83 & 0.04 & $0.99^{*}$ & 0.15 \\
\hline LVAWS;S & $\mathrm{mm}$ & 1.08 & 0.06 & 1.10 & 0.04 & $1.33^{*}$ & 0.15 \\
\hline LVID;d & $\mathrm{mm}$ & 3.25 & 0.08 & 3.59 & 0.11 & $2.64^{*}$ & 0.22 \\
\hline LVID;S & $\mathrm{mm}$ & 2.16 & 0.08 & 2.55 & 0.14 & $1.53^{*}$ & 0.24 \\
\hline LVPW;d & $\mathrm{mm}$ & 0.79 & 0.05 & 0.92 & 0.08 & $1.04^{*}$ & 0.07 \\
\hline LVPW;S & $\mathrm{mm}$ & 1.00 & 0.05 & 1.08 & 0.04 & $1.26^{*}$ & 0.11 \\
\hline Cardiac Output & $\mathrm{ml} / \mathrm{min}$ & 11.94 & 0.91 & 14.71 & 1.30 & $6.82^{*}$ & 1.32 \\
\hline Ejection Fraction & $\%$ & 67.72 & 1.78 & 57.87 & 3.73 & 76.10 & 6.35 \\
\hline Fractional Shortening & $\%$ & 36.94 & 1.33 & 30.05 & 2.51 & 45.31 & 6.28 \\
\hline Heart Rate & BPM & 381 & 18 & 471 & 21 & 352 & 23 \\
\hline Stroke Volume & ul & 30.62 & 1.56 & 31.30 & 2.33 & $18.91^{*}$ & 3.18 \\
\hline Volume;d & ul & 45.62 & 2.74 & 54.64 & 4.53 & $26.40^{*}$ & 5.53 \\
\hline \multirow[t]{2}{*}{ Volume;s } & ul & 15.00 & 1.47 & 23.34 & 3.47 & $7.49^{*}$ & 2.86 \\
\hline & & \multicolumn{2}{|c|}{$N=8 m, 4 f$} & \multicolumn{2}{|c|}{$N=4 m, 2 f$} & \multicolumn{2}{|c|}{$N=4 m, 2 f$} \\
\hline
\end{tabular}

LV left ventricle, AW anterior wall, ID internal diameter, PW posterior wall, $d$ diastolic, $s$ systolic, BPM beats per minute. ${ }^{*} p<0.05$ repeated measures ANOVA

\section{$\mu \mathrm{CT}$ assessment of heart vasculature}

Previous studies have shown that anthracycline chemotherapy causes vascular injury [13]. The mechanism of injury is thought to be via reactive oxygen species. To determine whether vascular injury is present in our mouse model of ACT, a subset of hearts from the first and third study underwent perfusion with Microfil and subsequent coronary vascular density measurements by

Table 3 Study II echocardiography

\begin{tabular}{|c|c|c|c|c|c|}
\hline \multirow[b]{3}{*}{ Parameter } & \multirow[b]{3}{*}{ Unit } & \multirow{2}{*}{\multicolumn{2}{|c|}{ BASELINE }} & \multirow{2}{*}{\multicolumn{2}{|c|}{$\frac{5 \text { weeks }}{\text { DOXORUBICIN }}$}} \\
\hline & & & & & \\
\hline & & $\overline{M E A N}$ & SE & MEAN & SE \\
\hline LVAW;d & $\mathrm{mm}$ & 0.88 & 0.08 & 0.70 & 0.09 \\
\hline LVAWS;S & $\mathrm{mm}$ & 1.25 & 0.11 & $0.80^{*}$ & 0.04 \\
\hline LVID;d & $\mathrm{mm}$ & 3.88 & 0.14 & 3.39 & 0.28 \\
\hline LVID;s & $\mathrm{mm}$ & 2.62 & 0.21 & 2.61 & 0.27 \\
\hline LVPW;d & $\mathrm{mm}$ & 0.89 & 0.03 & 0.79 & 0.08 \\
\hline LVPW;S & $\mathrm{mm}$ & 1.17 & 0.06 & $0.89^{*}$ & 0.04 \\
\hline Cardiac Output & $\mathrm{ml} / \mathrm{min}$ & 20.44 & 2.46 & $10.77^{*}$ & 3.12 \\
\hline Ejection Fraction & $\%$ & 62.50 & 5.03 & $49.80^{*}$ & 7.57 \\
\hline Fractional Shortening & $\%$ & 33.60 & 3.43 & $25.20^{*}$ & 4.66 \\
\hline Heart Rate & BPM & 488 & 17 & 400 & 49 \\
\hline Stroke Volume & $\mu l$ & 41.52 & 3.80 & $24.84^{*}$ & 5.53 \\
\hline Volume;d & $\mu l$ & 67.51 & 6.79 & 49.78 & 9.86 \\
\hline \multirow[t]{2}{*}{ Volume;s } & $\mu l$ & 26.00 & 5.35 & 24.94 & 6.24 \\
\hline & & \multicolumn{2}{|c|}{$N=3 \mathrm{~m}, 2 \mathrm{f}$} & \multicolumn{2}{|c|}{$N=3 \mathrm{~m}, 2 \mathrm{f}$} \\
\hline
\end{tabular}

$L V$ left ventricle, $A W$ anterior wall, ID internal diameter, $P W$ posterior wall, $d$ diastolic, s systolic, BPM beats per minute. ${ }^{*} p<0.05$, paired t-test $\mu \mathrm{CT}$. Mouse hearts exposed to doxorubicin lose coronaries with smaller diameters (Fig. 4). These data suggest endothelial damage.

\section{Liver and heart histological analysis}

One of the most striking observations was the clear differences in the liver size and structure at tissue harvest. The doxorubicin treated mice had significantly smaller

Table 4 Study III echocardiography

\begin{tabular}{|c|c|c|c|c|c|}
\hline \multirow[b]{3}{*}{ Parameter } & \multirow[b]{3}{*}{ Unit } & & & \multicolumn{2}{|c|}{5 weeks } \\
\hline & & \multicolumn{2}{|c|}{ CONTROL } & \multicolumn{2}{|c|}{ DOXORUBICIN } \\
\hline & & MEAN & SE & MEAN & SE \\
\hline LVAW;d & $\mathrm{mm}$ & 0.90 & 0.11 & 0.79 & 0.06 \\
\hline LVAWS;S & $\mathrm{mm}$ & 1.18 & 0.05 & 1.04 & 0.07 \\
\hline LVID;d & $\mathrm{mm}$ & 2.98 & 0.17 & $3.50^{*}$ & 0.16 \\
\hline LVID;S & $\mathrm{mm}$ & 1.69 & 0.14 & $2.50^{*}$ & 0.22 \\
\hline LVPW;d & $\mathrm{mm}$ & 1.03 & 0.14 & $0.81^{*}$ & 0.09 \\
\hline LVPW;S & $\mathrm{mm}$ & 1.40 & 0.12 & $1.10^{*}$ & 0.07 \\
\hline Cardiac Output & $\mathrm{ml} / \mathrm{min}$ & 15.2 & 1.0 & 16.3 & 0.8 \\
\hline Ejection Fraction & $\%$ & 79.8 & 3.8 & $60.0^{*}$ & 6.2 \\
\hline Fractional Shortening & $\%$ & 47.5 & 3.7 & $31.8^{*}$ & 4.1 \\
\hline Heart Rate & BPM & 556.6 & 29.4 & 484.3 & 11.7 \\
\hline Stroke Volume & ul & 27.4 & 2.0 & $33.6^{*}$ & 1.3 \\
\hline Volume;d & ul & 34.6 & 3.8 & $57.0^{*}$ & 4.7 \\
\hline \multirow[t]{2}{*}{ Volume;s } & ul & 7.3 & 2.1 & $23.4^{*}$ & 5.7 \\
\hline & & \multicolumn{2}{|c|}{$N=2 \mathrm{~m}, 2 \mathrm{f}$} & \multicolumn{2}{|c|}{$N=2 \mathrm{~m}, 2 \mathrm{f}$} \\
\hline
\end{tabular}

$L V$ left ventricle, $A W$ anterior wall, ID internal diameter, $P W$ posterior wall, $d$ diastolic, $s$ systolic, BPM beats per minute. ${ }^{*} p<0.05$ paired t-test 

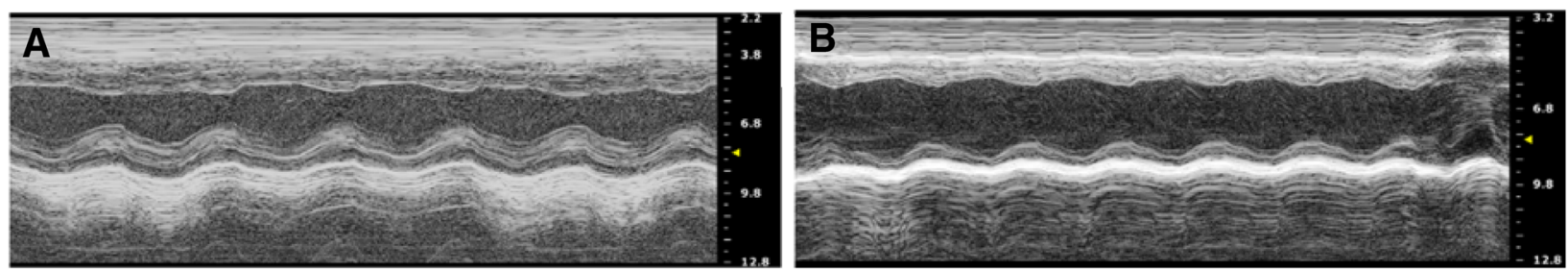

Fig. 2 Representative M-mode echocardiograms after 5 weeks of doxorubicin treatment in study III. a M-mode echocardiogram at baseline and $\mathbf{b}$ after 5 weeks of weekly $0.5 \mathrm{mg} / \mathrm{kg}$ doxorubicin injections

livers and hepatic structures appeared abnormal due to their smaller size. Histologically, there was marked hepatic plate atrophy with diminished cytoplasmic volume and both intracellular and canalicular cholestasis (Fig. 5). Fatty change or significant fibrosis was not seen. Native bile ducts appeared intact and there were no features of venous outflow obstruction. Only occasional hepatocellular dropout was evident, largely in pericentral distribution. Interestingly, there was significant iron accumulation, again predominantly pericentral (Fig. $5 \mathrm{c}$ and d). All of the above features point to metabolic/toxic liver injury that has been ongoing and is likely a direct effect of doxorubicin toxicity.

A subset of hearts was collected for histological assessment, specifically staining for Hematoxylin and Eosin (for structure and morphology) and Masson trichrome (for evidence of damage and fibrosis). Cardiac structure and morphology comparing the saline and doxorubicin treated mice were normal with no obvious disruption in cardiomyocytes (Fig. 6). Additionally, there was no increase in Masson trichrome staining in saline or doxorubicin hearts indicating no increased fibrosis or damage (Fig. 6).

\section{Discussion}

The purpose of this study was to develop a model of anthracycline-induced cardiotoxicity in an immune compromised mouse strain. The use of the NOD/Scid strain has not been characterized in this injury model and is essential for investigating the efficacy of human cell based therapies as a potential treatment for this type of cardiac injury. Over the course of this study, we determined that these mice have both systemic and cardiovascular susceptibility to anthracyclines. In addition to the cardiac toxicity, there was evidence of hepatic and gastrointestinal toxicity contributing to the decline of global health in the mice. Our results suggest that the mechanism of anthracycline-induced cardiac injury is potentially based on several different mechanisms and has a strong dependence on dosages used.

\section{Differences to other anthracycline studies in mice}

We have found a large variation in published studies using anthracyclines in mice regarding strain, dosing, total $\mathrm{cu}-$ mulative dose and dose timing, dependent on the goals of the experiment. Doses ranged from $2.5 \mathrm{mg} / \mathrm{kg}$ of body weight [14] to as high as $8 \mathrm{mg} / \mathrm{kg}$ [15]. Some doses were administered once, typically at a high dose, while other studies treated with multiple doses but
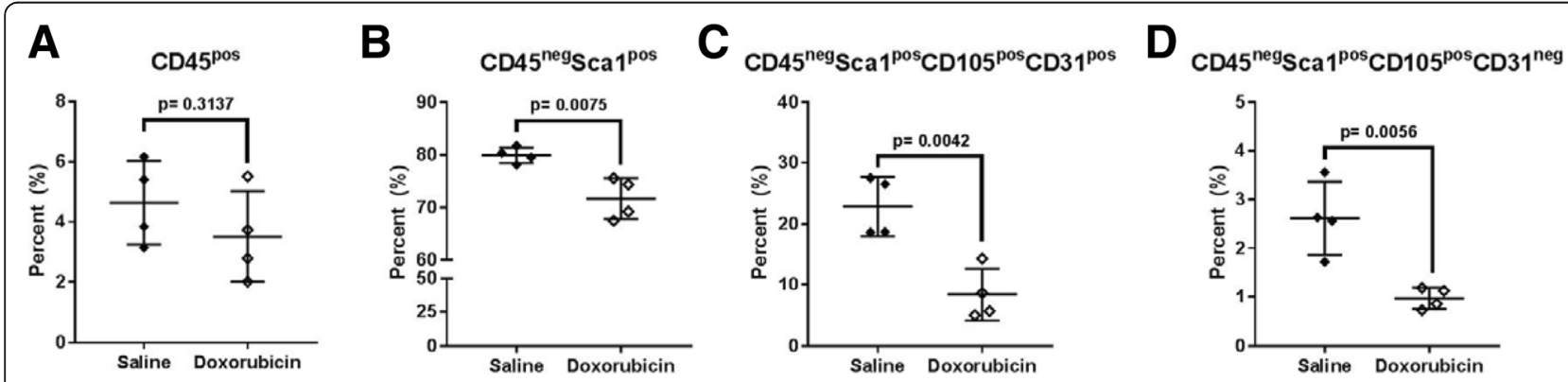

Fig. 3 Cardiac progenitor cell analysis following doxorubicin exposure in hearts from study I. a CD45 $5^{\text {pos }}$ immune cells were not different between groups. b $C D 45^{\text {neg }} S c a 1^{\text {pos }}$ non-immune cardiac cells were reduced in hearts with doxorubicin treatment. $\mathbf{c} C D 45^{\text {neg }} S c a 1^{\text {pos }} C D 105^{\text {pos }} C D 31^{\text {pos }}$ endothelial cell numbers are more than $50 \%$ lower in doxorubicin treated hearts. $\mathbf{d} C D 45^{\text {neg }} \mathrm{Sca} 1^{\text {pos }} \mathrm{CD} 105^{\text {pos }} \mathrm{CD} 31^{\text {neg }}$ cardiac progenitor cells are significantly decreased in hearts exposed to doxorubicin. Individual data points with mean and SD are shown. $N=4$, t-test with $p$ values indicated 

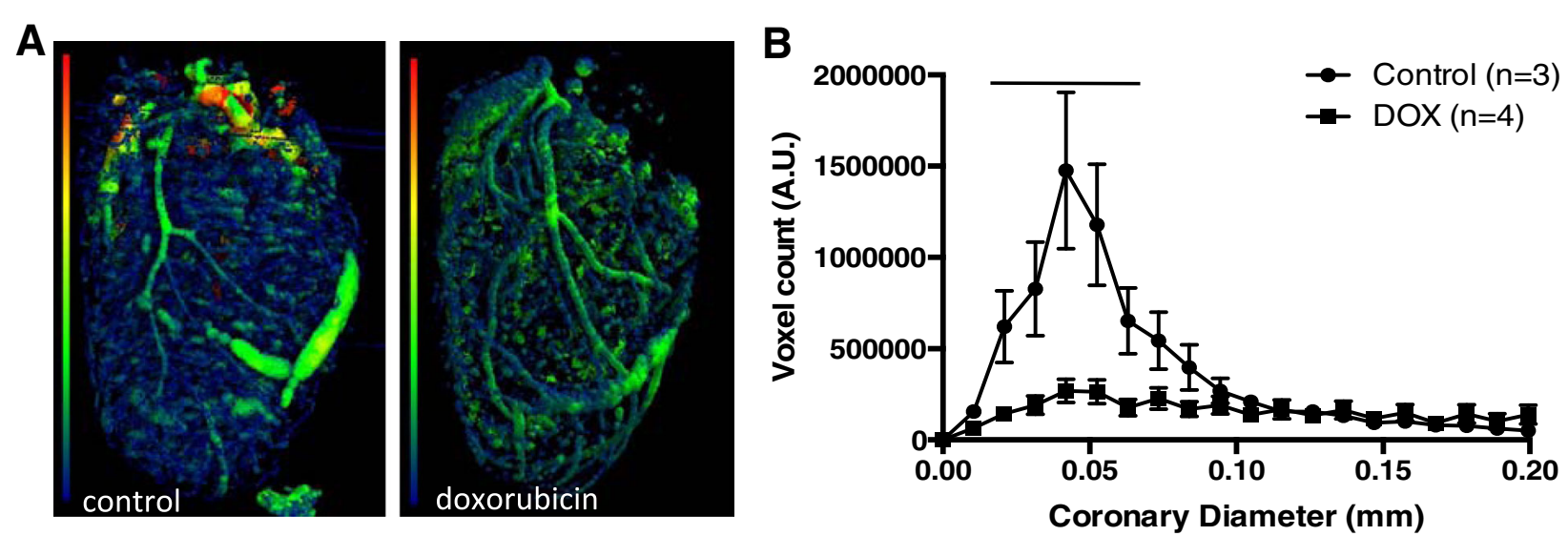

Fig. 4 Quantification of coronary blood vessels by $\mu C T$ in hearts from study I and III. a Representative $\mu C T$ images of Microfil perfused hearts. Saline injected control hearts show more of the smaller (dark blue) coronaries compared to doxorubicin exposed hearts. b Quantification of coronary diameters in saline and doxorubicin treated hearts. Saline treated hearts have a larger number of coronaries with smaller diameters compared to hearts from doxorubicin treated mice. MEAN $\pm \mathrm{SE}, n=3-4$, multiple t-test comparison with Sidak-Bonferroni correction for multiple comparisons, line indicates $p<0.05$

the time between doses varied widely. In addition, when immune compromised mouse strains were used, these studies focused on cancer research and not on chemotherapy-related cardiotoxicity. Another interesting observation is that most studies utilize nonpharmaceutical grade doxorubicin that is purchased lyophilized, which requires reconstitution and is then used at various doses. For this study, we chose pharmaceutical grade doxorubicin that did not require reconstitution, thus eliminating batch-to-batch variations in concentrations and we used the same grade that is being used in patients. However, we found that we needed much lower concentrations compared to studies performed by others.

\section{Systemic effects vs. cardiac effects - dosing considerations}

In our first two studies in NOD/Scid mice, we have found profound systemic toxicity of doxorubicin. The most highly affected organ systems were the intestines and the liver. This indicates that in NOD/Scid mice the gastrointestinal toxicity of doxorubicin is very pronounced and that these effects very likely contributed to the rapid decline of the mice in these studies. In study III, we used a very low dose of doxorubicin in order to avoid the toxic systemic effects. Mice tolerated this very low dose without any signs of distress and had only modest body weight loss. As mentioned, 2 days prior to completion of the time course all mice declined rapidly and either died or had to be euthanized. We did not observe intestinal mucositis in these mice, but all mice showed signs of hepatic toxicity. The observed histologic changes can be entirely attributed to metabolic liver toxicity of doxorubicin. This is true both globally, as the observed, significant liver cell atrophy appeared rather diffuse in distribution, as well as zonal along the cytochrome P450 enzyme activation distribution within the liver. The observed iron accumulation is likely a secondary phenomenon due to a metabolic compromise, mirroring the more acute hepatocellular damage found predominantly in zone 3 .

In addition to the hepatic toxicity, this last cohort showed signs of cardiac toxicity at the 5 week time point. For these mice, it is difficult to determine if the liver toxicity or the cardiac toxicity was responsible for their decline. In other studies investigating ACT, the systemic effects that we have observed have not been mentioned, raising the question whether this is a strain specific effect.

The disrupted immune system in this NOD/Scid strain causes a lack of adaptive immunity and impairs the innate immunity due to natural killer (NK) cell deficiency and impaired T and B cells. Given the high susceptibility to systemic toxicity, the lack of the adaptive immune response may play a role in this injury model. The Scid mutation results in the $B$ and $T$ cell deficiency due to mutation in the Prkdc protein, which is involved in the DNA repair processes [16]. In addition, the IL2rg mutation hinders multiple interleukin signaling cascades and thus results in a lack of functional NK cells [16]. There is limited knowledge on the adaptive immune response in the context of anthracycline use but the role of the adaptive immune response has been investigated in the context of ischemic cardiac injury. The adaptive immune response is shown to play pivotal roles in aiding the innate immune response following ischemic cardiac injury [17]. Studies performed in other models of cardiac injury (such as a myocardial infarction model) may lend insight 


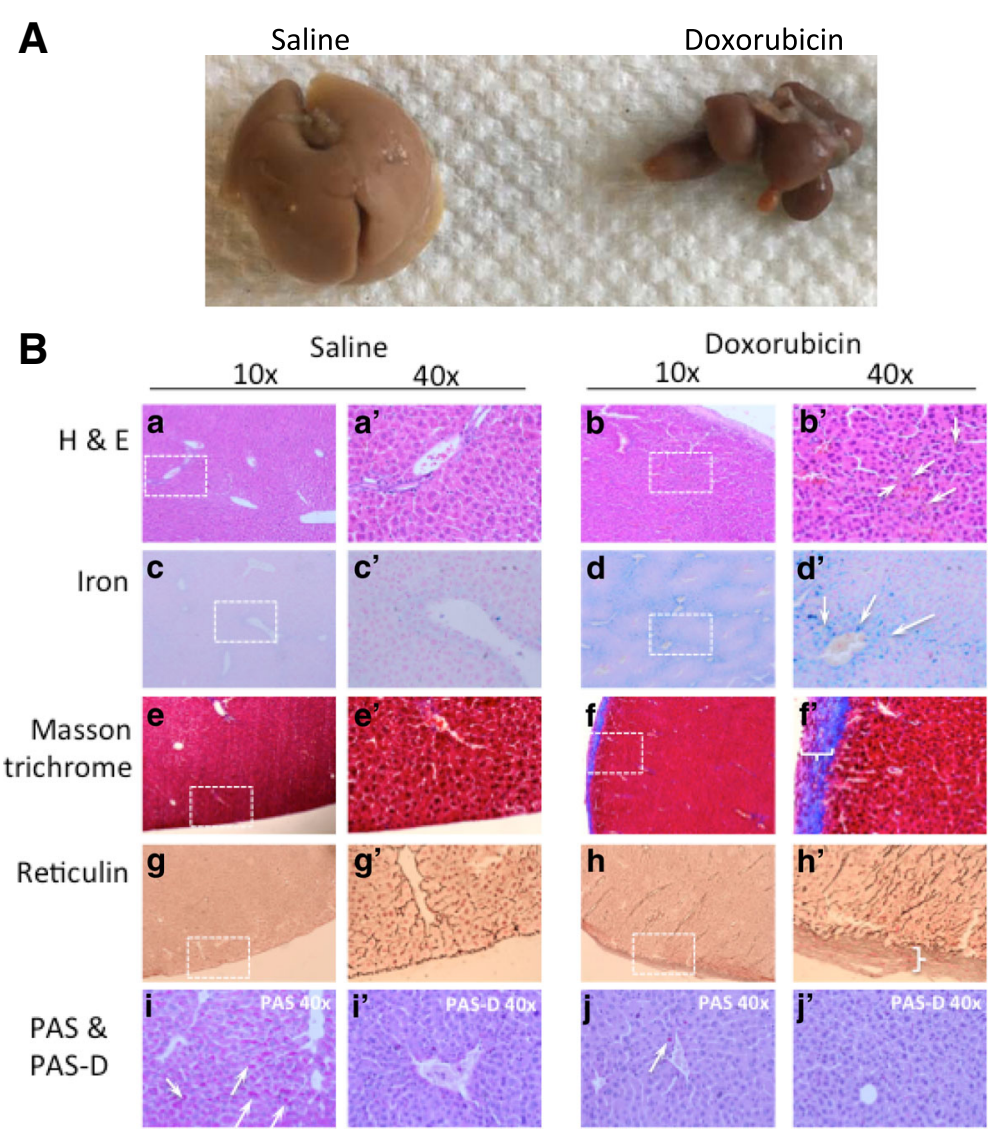

Fig. 5 Liver morphology and histology of saline and doxorubicin injected NOD/Scid mice. a Gross morphology of the liver from saline and doxorubicin injected mice. The liver from the doxorubicin-injected mouse was the worst case observed, however varying degrees of liver atrophy were observed in all animals from all three studies. $\mathbf{b}$ a, a', b and b': H \& E stain of liver showing hemosiderin deposits (b', brown staining/white arrows) in the doxorubicin exposed liver. $c, c^{\prime}, d$ and d': Iron staining confirms deposition of hemosiderin ( $d$ and d', blue stain/white arrows) throughout the liver in doxorubicin treated mice. $e, e^{\prime}, f$ and $f^{\prime}$ : Masson trichrome staining reveals a thickened fibrous capsule in doxorubicin treated mice (f', white brackets). $g, g^{\prime}, h$ and $h^{\prime}$ : Reticulin staining confirms a thick fibrous cap in doxorubicin treated mice ( $h^{\prime}$, white bracket). i, i', j and j': PAS and PAS-D staining to show the presence or absence of glycogen stores. Saline treated mice show red staining in their livers (i, white arrows), which disappears with dispase treatment (i', PAS-D). Doxorubicin treated mice do not show staining with PAS, suggesting depleted hepatic glycogen stores ( $j$ and $j$ '). Representative images shown from study III mice

into the role of the adaptive and innate immune responses in an anthracycline-induced cardiotoxicty model as well as the systemic susceptibility the mice in our study demonstrated. Further investigation in the immune response may elucidate mechanisms contributing to the systemic and cardiac toxicity caused by anthracycline therapy.

\section{Discussion of potential mechanism - endothelial vs. cardiomyocyte}

Despite the systemic side effects and the significant hepatic toxicity, the results of our study suggest that the cardiac insult from anthracyclines may not solely be caused by cardiomyocyte toxicity as suggested by other studies [2]. While we have not found damage to the cardiomyocytes based on histological assessment, we can not exclude some of the previously suggested mechanisms such as disruption to sarcomere structure [18] or oxidative stress to cardiomyocytes [19]. Our study suggests that as a further injury mechanism, the cardiac endothelium seems to be a primary target of the toxic chemotherapeutic effects. The more than $50 \%$ loss of cardiac endothelial cells and the significant lower number of small diameter coronary blood vessels support this conclusion. The loss of endothelial cells can alter vessel permeability and increased permeability can result in increased inflammatory infiltration and alter contractility of the myocardium [20, 21]. In study I via flow cytometry, we found no significant differences in $C D 45^{\text {pos }}$ immune cells after 2 weeks of doxorubicin treatment but this may change if we looked at a later time point in the study after chemotherapy treatment is completed since the immune system can be altered 


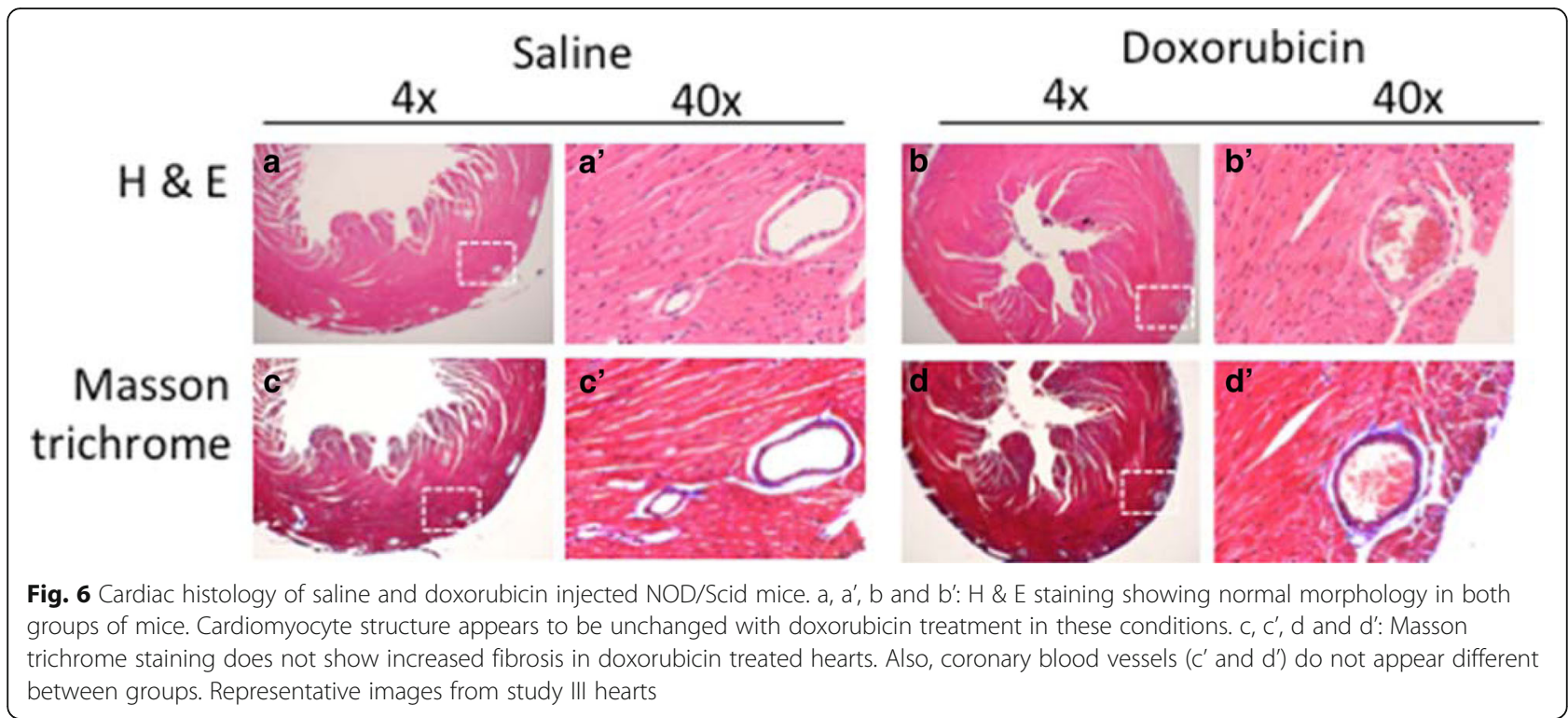

during chemotherapy administration [22]. In addition, the loss of cardiac progenitor cells may predispose these hearts to a long-term loss of cardiac repair potential. Cardiac progenitor cells are considered a reserve pool to aide in repair of the damaged cells within the heart. Cardiac progenitor cells are capable of differentiating into mature cardiac myocytes, endothelial cells, and fibroblasts. Loss of this pool would limit the heart's capability to replace the cells lost following chemotherapy exposure. This may provide one explanation why some cancer survivors develop heart failure years after completion of their chemotherapy.

Preclinical models to investigate the efficacy of cell-based therapy for treating anthracycline-induced cardiac injury in cancer survivors are needed. With this study identifying a model of vascular toxicity instead of cardiac myocyte toxicity, we have a model to further test the efficiency of cell-based therapies to restore endothelial cell number and vascular function. Our group has previously isolated highly proliferative cells from epicardial left ventricular biopsies (eHiPCs) in patients undergoing coronary artery bypass grafting surgery [23]. We identified a subset of these eHiPCs that exhibit endothelial-like properties and are currently undergoing further characterization to determine their potential for revascularization. These cells may prove to be quality candidates to test in future studies as a therapy for the vascular toxicity associated with ACT.

\section{Conclusions}

In summary, we have established an immune compromised mouse model for doxorubicin-induced cardiovascular toxicity using NOD/Scid mice by administering very low doses of pharmaceutical grade doxorubicin. Utilizing this model in NOD.Cg-Prkdc ${ }^{\text {scid }} \mathrm{Il} 2 \mathrm{rg}^{\mathrm{tm} 1 \mathrm{~W} / \mathrm{l}} / \mathrm{SzJ}$ mice may allow us to investigate the efficacy of progenitor cell based therapies to alleviate established cardiotoxic damage specifically to vessels and progenitors. It should be recognized that close observation is required with this strain, specifically checking on these mice for signs of gastrointestinal distress, lethargy, dehydration, and loss of appetite. At study endpoint, examining mice for intestinal complications and liver toxicity should be performed and noted as these could contribute to the phenotype. Any such complications on a systemic level should be considered when drawing conclusions even though the main purpose of the study is to focus on the cardiac damage from anthracyclines. This study provides a basis to explore cell-based treatment options for long-term cancer survivors with chemotherapy-induced heart failure to overcome, the often fatal, consequences of cytotoxic cancer therapies.

\section{Abbreviations}

ACT: Anthracycline-induced cardiotoxicity; AW: Anterior wall; BPM: Beats per minute; d: diastolic; H\&E: Hematoxylin and Eosin; ID: Internal diameter;

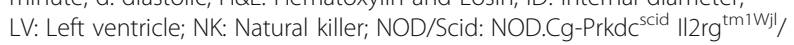
SzJ; PW: Posterior wall; s: systolic

\section{Acknowledgements}

This study utilized the services of the Core Facilities (Histopathology \& Histomorphometry Core, Progenitor Cell Analysis Core, and Mouse Transgenic \& In Vivo Imaging Core) funded by the National Institutes of Health grant U54GM115516 - Northern New England Clinical and Translational Research Network, grant P20GM121301 - COBRE in Mesenchymal and Neural Regulation of Metabolic Networks, and grant P30GM106391 - COBRE in Stem and Progenitor Cell Biology and Regenerative Medicine.

\section{Funding}

This work was supported in part by the Melvyn and Carolyn Miller Family Fund. This work was also supported by an American Heart Association Postdoctoral Research Fellowship Training Award (17POST33410474) to AFL. 


\section{Availability of data and materials}

All data generated or analyzed during this study are included in this published article.

\section{Authors' contributions}

AFL and IMP designed and performed the experiments, analyzed data and constructed the manuscript. HB and MJ provided expertise in liver pathology, analysis of liver histological assessment, and manuscript review. DBS contributed to experimental design, data interpretation, and manuscript review. All authors read and approved the final manuscript.

\section{Ethics approval}

All mouse studies were approved by the Maine Medical Center Research Institute's Institutional Animal Care and Use Committee.

\section{Consent for publication}

Not applicable.

\section{Competing interests}

The authors declare that they have no competing interests.

\section{Publisher's Note}

Springer Nature remains neutral with regard to jurisdictional claims in published maps and institutional affiliations.

\section{Author details}

${ }^{1}$ Maine Medical Center Research Institute, Center for Molecular Medicine, 81 Research Drive, Scarborough, ME 04074, USA. ²Pathology Department, Maine Medical Center, 22 Bramhall St, Portland, ME 04102, USA. ${ }^{3}$ Maine Medical Center, Cardiovascular Services, 22 Bramhall St, Portland, ME 04102, USA.

Received: 11 March 2019 Accepted: 10 April 2019

Published online: 25 April 2019

\section{References}

1. Bluethmann SM, Mariotto $A B$, Rowland JH. Anticipating the "silver tsunami": prevalence trajectories and comorbidity burden among older Cancer survivors in the United States. Cancer Epidemiol Biomark Prev. 2016;25(7): 1029-36.

2. Geisberg CA, Sawyer DB. Mechanisms of anthracycline cardiotoxicity and strategies to decrease cardiac damage. Curr Hypertens Rep. 2010;12(6):404-10.

3. Carvalho C, Santos RX, Cardoso S, Correia S, Oliveira PJ, Santos MS, Moreira PI. Doxorubicin: the good, the bad and the ugly effect. Curr Med Chem. 2009;16(25):3267-85

4. Tan C, Tasaka H, Yu KP, Murphy ML, Karnofsky DA. Daunomycin, an antitumor antibiotic, in the treatment of neoplastic disease. Clinical evaluation with special reference to childhood leukemia. Cancer. 1967;20(3): 333-53

5. Ritchie JL, Singer JW, Thorning D, Sorensen SG, Hamilton GW. Anthracycline cardiotoxicity: clinical and pathologic outcomes assessed by radionuclide ejection fraction. Cancer. 1980;46(5):1109-16.

6. Olson LE, Bedja D, Alvey SJ, Cardounel AJ, Gabrielson KL, Reeves RH. Protection from doxorubicin-induced cardiac toxicity in mice with a null allele of carbonyl reductase 1. Cancer Res. 2003;63(20):6602-6.

7. Feleszko W, Mlynarczuk I, Balkowiec-Iskra EZ, Czajka A, Switaj T, Stoklosa T, et al. Lovastatin potentiates antitumor activity and attenuates cardiotoxicity of doxorubicin in three tumor models in mice. Clin Cancer Res. 2000;6(5): 2044-52.

8. Zhang S, Liu X, Bawa-Khalfe T, Lu LS, Lyu YL, Liu LF, et al. Identification of the molecular basis of doxorubicin-induced cardiotoxicity. Nat Med. 2012; 18(11):1639-42.

9. Kang YJ, Chen Y, Epstein PN. Suppression of doxorubicin cardiotoxicity by overexpression of catalase in the heart of transgenic mice. J Biol Chem. 1996;271(21):12610-6.

10. Talukder MA, Preda M, Ryzhova L, Prudovsky I, Pinz IM. Heterozygous caveolin-3 mice show increased susceptibility to palmitate-induced insulin resistance. Phys Rep. 2016:4(6);1-14.

11. Knowles CJ, Cebova M, Pinz IM. Palmitate diet-induced loss of cardiac caveolin-3: a novel mechanism for lipid-induced contractile dysfunction. PLoS One. 2013;8(4):e61369.
12. Desai VG, Lee T, Moland CL, Vijay V, Han T, Lewis SM, et al. Candidate early predictive plasma protein markers of doxorubicin-induced chronic cardiotoxicity in B6C3F1 mice. Toxicol Appl Pharmacol. 2019;363:164-73.

13. Rasanen M, Degerman J, Nissinen TA, Miinalainen I, Kerkela R, Siltanen A, et al. VEGF-B gene therapy inhibits doxorubicin-induced cardiotoxicity by endothelial protection. Proc Natl Acad Sci U S A. 2016;113(46):13144-9.

14. Yalcin E, Oruc E, Cavusoglu K, Yapar K. Protective role of grape seed extract against doxorubicin-induced cardiotoxicity and genotoxicity in albino mice. J Med Food. 2010;13(4):917-25.

15. Wang X, Wang XL, Chen HL, Wu D, Chen JX, Wang XX, et al. Ghrelin inhibits doxorubicin cardiotoxicity by inhibiting excessive autophagy through AMPK and p38-MAPK. Biochem Pharmacol. 2014;88(3):334-50.

16. Shultz LD, Lyons BL, Burzenski LM, Gott B, Chen X, Chaleff S, et al. Human lymphoid and myeloid cell development in NOD/LtSz-scid IL2R gamma null mice engrafted with mobilized human hemopoietic stem cells. J Immunol. 2005; 174(10):6477-89.

17. Santos-Zas I, Lemarié J, Tedgui A, Ait-Oufella H. Adaptive immune responses contribute to post-ischemic cardiac remodeling. Front Cardiovasc Med. 2019;5(198):1-9.

18. Chen B, Zhong L, Roush SF, Pentassuglia L, Peng X, Samaras S, et al. Disruption of a GATA4/Ankrd1 signaling axis in cardiomyocytes leads to sarcomere disarray: implications for anthracycline cardiomyopathy. PLoS One. 2012;7(4):e35743.

19. Zhou S, Palmeira CM, Wallace KB. Doxorubicin-induced persistent oxidative stress to cardiac myocytes. Toxicol Lett. 2001;121(3):151-7.

20. Wolf MB, Baynes JW. The anti-cancer drug, doxorubicin, causes oxidant stress-induced endothelial dysfunction. Biochim Biophys Acta. 2006; 1760(2):267-71.

21. Claesson-Welsh L. Vascular permeability--the essentials. Ups J Med Sci. 2015; 120(3):135-43.

22. Zitvogel L, Kepp O, Kroemer G. Immune parameters affecting the efficacy of chemotherapeutic regimens. Nat Rev Clin Oncol. 2011;8(3):151-60.

23. Ryzhov S, Robich MP, Roberts DJ, Favreau-Lessard AJ, Peterson SM, Jachimowicz E, et al. ErbB2 promotes endothelial phenotype of human left ventricular epicardial highly proliferative cells (eHiPC). J Mol Cell Cardiol. 2018;115:39-50

\section{Ready to submit your research? Choose BMC and benefit from:}

- fast, convenient online submission

- thorough peer review by experienced researchers in your field

- rapid publication on acceptance

- support for research data, including large and complex data types

- gold Open Access which fosters wider collaboration and increased citations

- maximum visibility for your research: over $100 \mathrm{M}$ website views per year

At BMC, research is always in progress.

Learn more biomedcentral.com/submissions 